\title{
Telavancin Hydrochloride
}

National Cancer Institute

\section{Source}

National Cancer Institute. Telavancin Hydrochloride. NCI Thesaurus. Code C87636.

The hydrochloride salt form of telavancin, a lipoglycopeptide and a semisynthetic derivative of vancomycin with antibacterial activity ag ainst gram-positive bacteria. Like vancomycin, telavancin binds tightly to the D-alanyl-D-alanine residue of cell wall precursors, thereby interfering with bacterial cell wall synthesis. In addition, the lipophilic moiety of telavancin may interact with the lipid bilayer in the bacterial cell membrane, thereby compromising the integrity of cell membrane and causing cell membrane depolarization. This novel mechanism of action may contribute to telavancin's rapid bactericidal activity and its improved activity over vancomycin ag ainst some antibiotic resistance gram-positive bacteria. 